\title{
SIMULATION AND PROJECT OF HIGH FREQUENCY TRANSFORMER APPLIED TO A PLASMA PLANT
}

\author{
Giancarlos Costa Barbosa ${ }^{1}$, Andrés Ortiz Salazar ${ }^{2}$, Jean Paul Dubut ${ }^{3}$, José Alberto Díaz Amado ${ }^{4}$ \\ ${ }^{1}$ Instituto Federal do Rio Grande do Norte - IFRN - Campus Caicó - Rodovia RN 288 s/no - 59300-000 - Caicó - RN - Brasil \\ ${ }^{2}$ Universidade Federal do Rio Grande do Norte - UFRN - Campus Universitário, s/no - 59072-970 - Natal - RN - Brasil \\ ${ }^{3}$ Instituto Nacional de Pesquisas Espaciais - INPE/CRN - Av. Salgado Filho, no 3000 - Caixa Postal 130 - 59001-970 - Natal - \\ $\mathrm{RN}$ - Brasil \\ ${ }^{4}$ Instituto Federal da Bahia - Campus Vitória da Conquista - Av. Amazonas, no 3150 - 45075-265 - Vitória da Conquista - BA - \\ Brasil \\ '19iancarlos.barbosa@ifrn.edu.br, ${ }^{2}$ andres@dca.ufrn.br, ${ }^{3}$ jean@crn.inpe.br, ${ }^{4}$ jose_diaz@ifba.edu.br
}

\begin{abstract}
This paper describes the project of a transformer with PCB (Printed Circuit Board) windings (50 kW operating at the nominal frequency of $450 \mathrm{kHz}$ ) for using in a plasma inertization plant. The plant is composed basically of RF (Radio Frequency) power supply and a ICP (Inductively Coupled Plasma) torch. The transformer will make the coupling between the RF power supply and the ICP torch. To evaluate the performance of the transformer will be made simulations taking into account parameters such as temperature, magnetic flux density, waveform voltage and parasitic effects.
\end{abstract}

Keywords - ICP torch, PCB windings, Series Resonant Inverter, Transformer, 3D Simulation.

\section{INTRODUCTION}

One of the most serious ecological problems faced by the humanity is the environment pollution by residues generated in the production process and use of goods such as: residues produced of raw materials and rendered services; urban waste and sewer, and used goods that should be discarded, besides the residues originated in the sanitary sewer treatment.[1]

One solution to this problem is to eliminate these products cleanly and safely. Thermal treatment technologies have been widely used to treat these residues and thermal plasma has been gaining importance in the processing of dangerous residues. Plasma complements or substitutes traditional technologies, is a clean, definitive, safe and competitive option, and, more importantly, does not generate any other residues.

A toxic waste inertization plant is currently in the development phase. The plant is composed of an ICP torch, two reactors (main and secondary), a torch refrigeration system, a gas cleaning system, a gas exhaust system and a feed source operating in the radio frequency range.[2] The $\mathrm{RF}$ power supply is composed of a three-phase AC-DC boost converter and a single-phase DC-AC series resonant inverter. The diagram of plasma inertization plant, including the transformer, is shown in Figure 1.

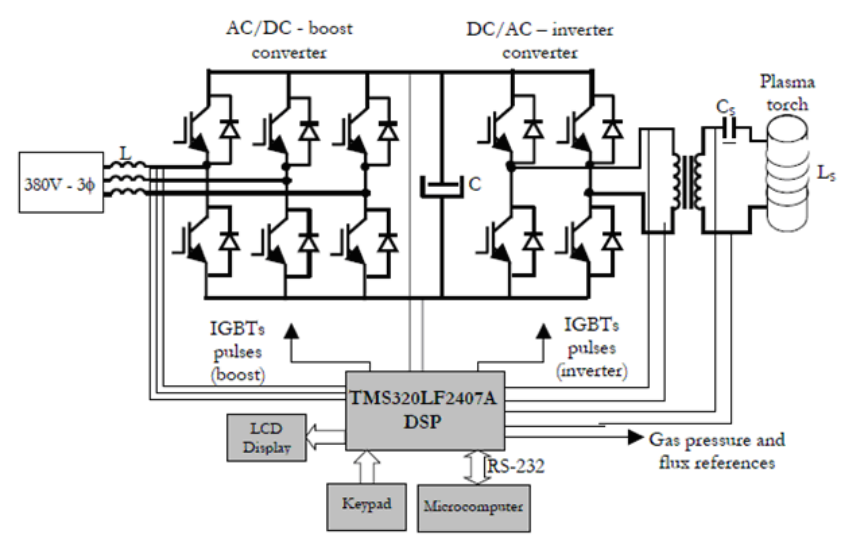

Fig. 1. Diagram of plasma inertization plant.

This study is the development of a transformer that has excellent performance at high frequencies $(450 \mathrm{kHz})$ and power $(50 \mathrm{~kW})$, which permits the impedance matching between the RF power supply and the main reactor (plasma torch) ensuring the transfer energy with minimum losses.

The transformer with PCB windings was chosen because of the following characteristics: excellent performance at high frequencies, reduction of parasitic reactances and the skin effect.[3]

For purposes of analysis, we used a software, Ansoft MAXWELL $\AA 3 D$, where the transformer was subjected to the desired operating conditions.

\section{SERIES RESONANT INVERTER}

Four identical $50 \mathrm{~kW}$ inverters constitute the main part of the high frequency series resonant converter. Each inverter structure is rated to the nominal value of $50 \mathrm{~kW}$ and uses a dual SEMIKRON SKM100GB125DN ultra-fast IGBT module.[4]

The Figure 2 shows the simplified circuit diagram of the high frequency series resonant converter and its principal connections with the resonant load and the DSP module. 


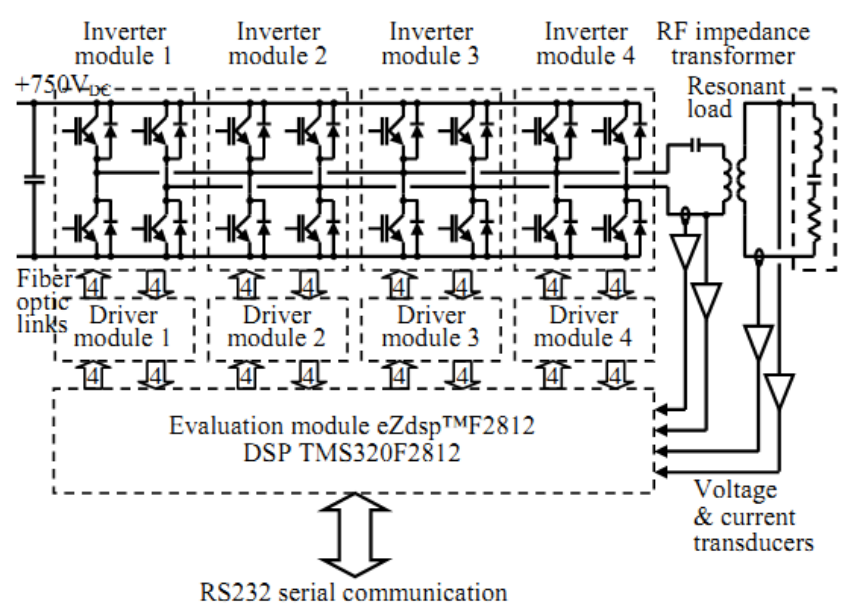

Fig. 2. Simplified circuit diagram of the high frequency series resonant load converter.

The full-bridge resonant inverters are designed to constitute a modular system. In order to minimize the parasitic inductances and provide a better space arrangement, the four inverter modules are vertically grouped and distributed around the DC bus, assuring the necessary symmetry to the inverter set. The high frequency transformer is built on a ferrite $\mathrm{C}$ core with the primary and secondary windings constituted by PCB. In Figure 3 can be seen the waveforms of the inverter output.

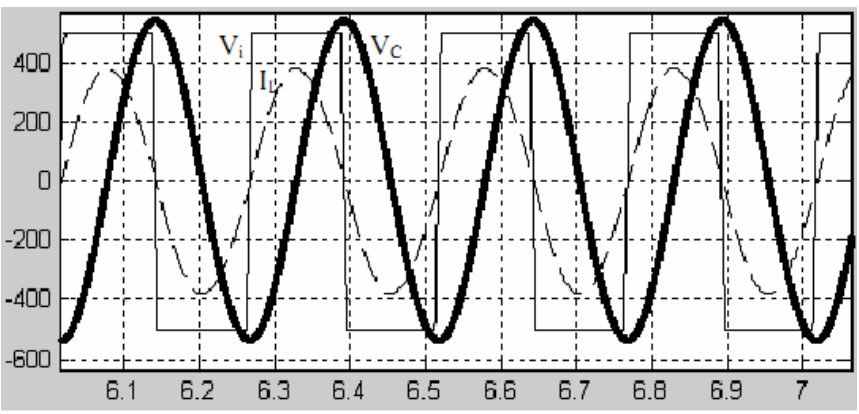

Fig. 3. Output inverter waveforms.

\section{POWER LOSSES IN TRANSFORMERS}

The losses of a transformer are related to its windings and its magnetic core, including the loss by skin effect and eddy current. Such losses are the difference between the power in the primary winding of the transformer and power in load.

The magnetic losses in ferrite cores $\left(P_{m}\right)$ were calculated according to the frequency $(f$ in $\mathrm{Hz})$, peak magnetic flux density $\left(B\right.$ in T) and temperature $\left(T_{n}\right.$ in $\left.{ }^{\circ} \mathrm{C}\right)$, can be obtained by (1):

$$
P_{m}=C_{m} f^{x} B^{y} C T\left(T_{n}\right)
$$

Where $C_{m}, x$, and $y$ are the constants for the material and $C T$, the correction factor for losses as a function of temperature, is given by (2):

$$
C T\left(T_{n}\right)=c t_{0}-c t_{1} T_{n}+c t_{2} T_{n}^{2}
$$

Where $c t_{0}, c t_{1}$ e $c t_{2}$ are the constants dependents of magnetic losses in core.

\section{PROJECT OF TRANSFORMER}

For the design of the transformer is needed specifies the effective $(r m s)$ values of voltages in primary $\left(V_{\text {lrms }}\right)$ and secondary $\left(V_{2 r m s}\right)$ windings, the effective value of current in secondary $\left(I_{2 r m s}\right)$, the frequency and temperature.[5]

The design begins with the choice of the core to be used. For the transformer in study were used ferrite cores of material IP6 of Thornton. We used 16 cores of the type NC$100 / 57 / 25$ so that the arrangement of these form a core equivalent to the type $\mathrm{E}$. It is estimated, then the maximum number of conductive layers, the of turns per layer and total turns. These values are limited by the geometric dimensions of the core and depend on the technology used for the manufacture of circuit boards in which the windings are printed. The maximum number of conducting layers is given by (3):

$$
N_{W}=\frac{h_{W}-\sum h_{i}}{h_{p c b}} N_{f}
$$

The Table I describes the symbols used in (3).

TABLE I

Symbols used in (3)

\begin{tabular}{cc}
\hline Symbol & Quantity \\
\hline$N_{W}$ & $\begin{array}{c}\text { Number of conductive } \\
\text { layers }\end{array}$ \\
$h_{W}$ & $\begin{array}{c}\text { Height of the window } \\
\text { of the core }\end{array}$ \\
$\sum h_{i}$ & $\begin{array}{c}\text { Sum of the isolations } \\
\text { Thickness of PCB } \\
h_{p c b}\end{array}$ \\
$N_{f}$ & $\begin{array}{c}\text { (Printed Circuit Board) } \\
\text { fumber of conductive } \\
\text { faces of PCB }\end{array}$ \\
\hline
\end{tabular}

Due to the use of coupling, the turns ratio between primary and secondary transformer was defined by a ratio of $3: 1$, as the RF power supply has an impedance of $12 \Omega$ and the plasma torch to an impedance of $1.5 \Omega$.

For the accomplishment of the work were available printed circuit board with double layers of copper with thickness of $70 \mu \mathrm{m}$. We used an equal number of conductive layers for both windings, so each coil was with 12 conductive layers (six PCB). In each conductive layer is only used one turn.

The primary winding consists of three turns, had each of its turns placed on two printed circuit boards connected in parallel, and these turns connected in series. Since the 
secondary winding consists of one turn had its six boards connected in parallel.

It was observed that in range of 60 to $80{ }^{\circ} \mathrm{C}$, the transformer operates with minimal losses. The specified and calculated values of transformer are shown in Table II.

With these data it was possible to implement a prototype of the transformer shown in Figure 4.

TABLE II

Specified and Calculated Values

\begin{tabular}{cc}
\hline \hline Specified Values & Values \\
\hline Frequency (kHz) & 450 \\
Voltage of Primary (V) & 800 \\
Voltage of Secundary (V) & 260 \\
Current of Secondary(A) & 186 \\
Chosen Core & NC $100 / 57 / 25$ \\
\hline Calculated Values & Values \\
\hline Number of turns of Primary & 3 \\
Number of turns of Secondary & 1 \\
Track width of Primary (mm) & 45 \\
Track width of secondary (mm) & 45 \\
Temperature $\left({ }^{\circ} \mathrm{C}\right)$ & 68 \\
\hline
\end{tabular}

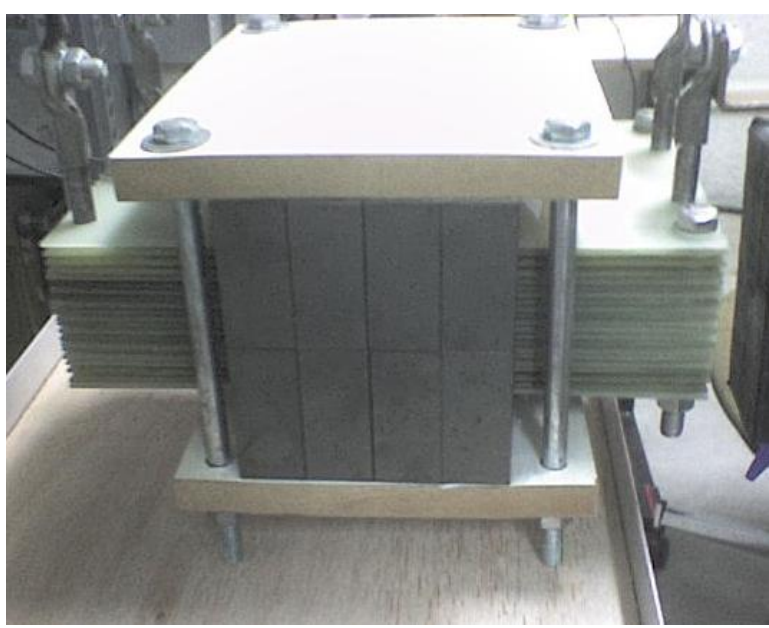

Fig. 4. Prototype of Transformer.

\section{SIMULATIONS}

The software Ansoft MAXWELL $® 3 \mathrm{D}$, that it is based on the analysis of finite elements, it was used in the simulations. The simulations were done considering a resistive load and sinusoidal supply.

All the following analysis is based on energy losses, the behavior of the field and the magnetic induction and current density. As previously mentioned, the total losses are the difference between the primary power transformer and power the load are obtained through (4).

$$
P_{t o t}=\frac{1}{T} \int_{0}^{T}\left[V_{1}(t) I_{1}(t)-V_{L}(t) I_{L}(t)\right] d t
$$

It is possible to visualize in Figures 5 and 6 the values of voltages and currents in both windings.

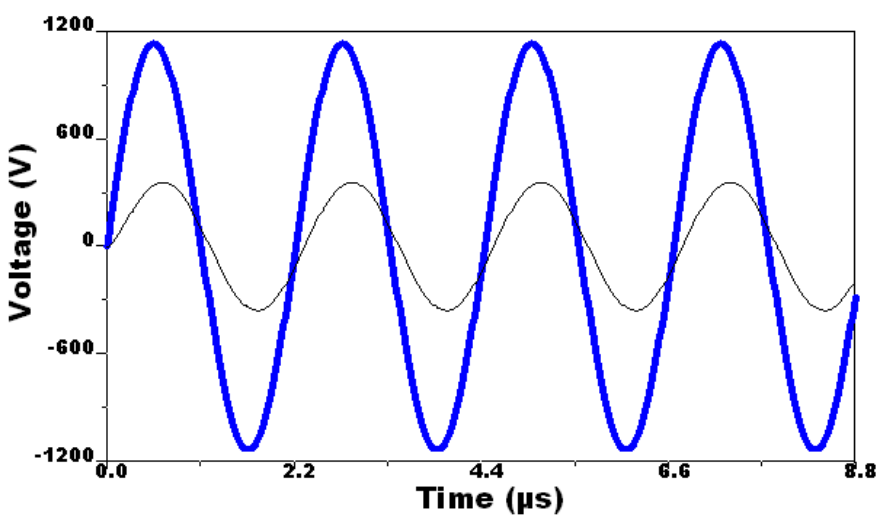

Fig. 5. Waveforms of voltages in winding primary (blue line) and winding secondary (black line).

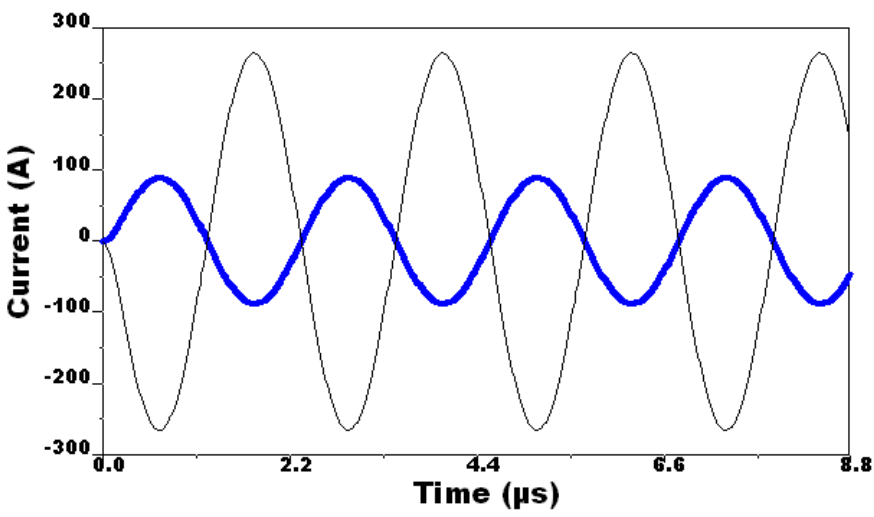

Fig. 6. Waveforms of currents in winding primary (blue line) and winding secondary (black line).

From the values of voltage and current is possible to obtain the power values in the input transformer and its output. Thus, it was found that the transformer has an efficiency of about $94.4 \%$ in the simulations. In simulations was done using of (1) for the calculation of losses in the magnetic core. The software provides a tool in the user enter only the values of the constants and it displays the results. With these values of losses you can check the operating temperature of the transformer in which there is minimal losses. According to Figure 7, it can be observed that the losses occur at a minimum temperature around $68{ }^{\circ} \mathrm{C}$, reaching a value of about $41.3 \mathrm{~W}$. 


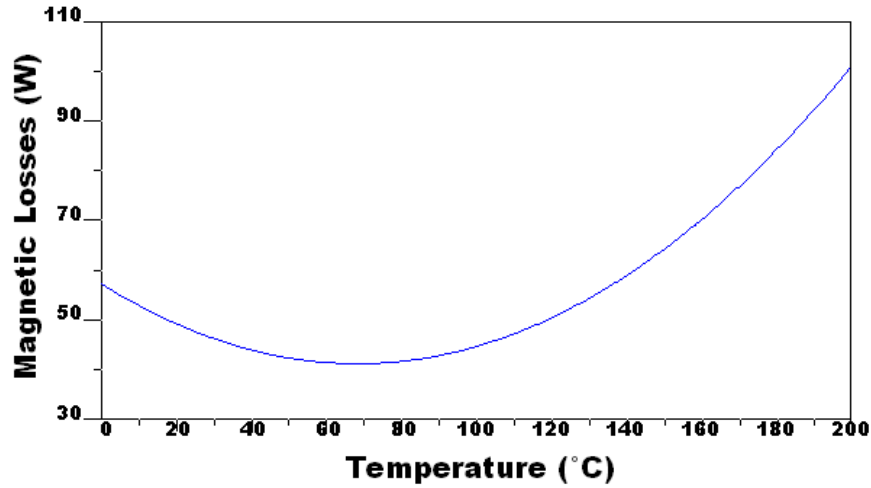

Fig. 7. Core losses in function of temperature.

It is possible to also find the values of losses in the windings. As these coils have low impedance, the losses will be low. It was found a value of approximately $17 \mathrm{~W}$. In the situation of operation indicated, the values of the vector magnetic flux density normal to the surface of the central core of the transformer can be seen in Figure 8.

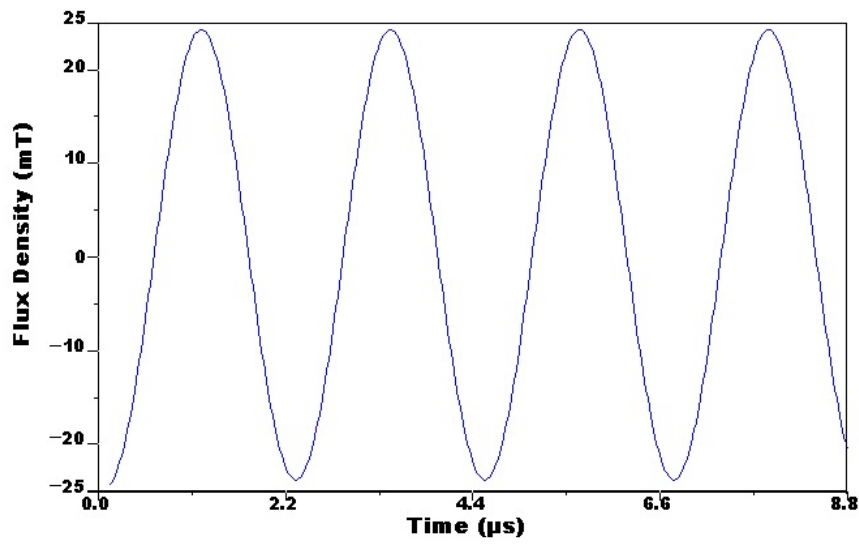

Fig. 8. Flux density in transformer.

In order to show the best distribution of current in the windings, we generated the Figures 9 and 10.
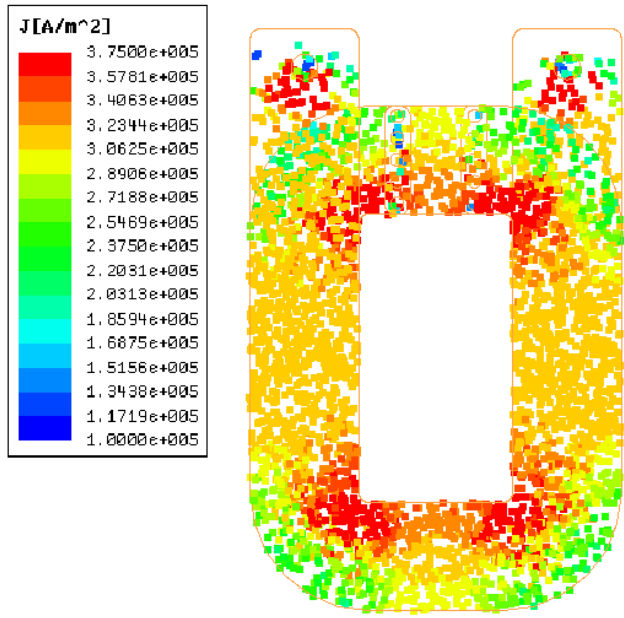

Fig. 9. Current density in the primary winding.
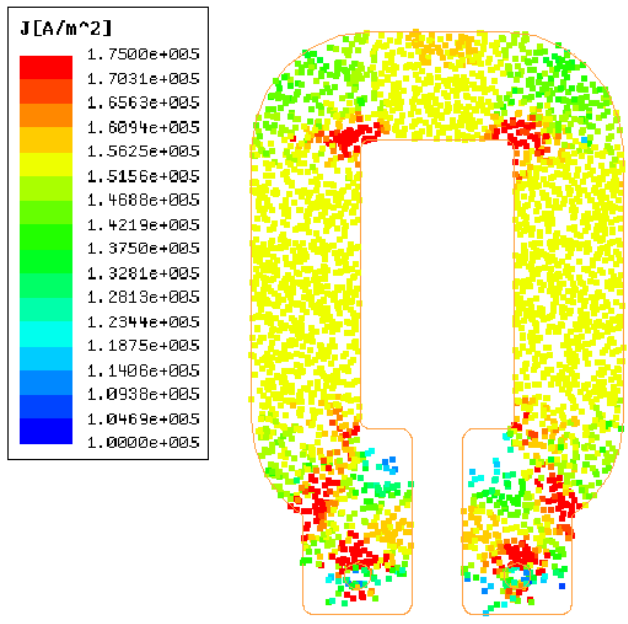

Fig. 10. Current density in the secondary winding.
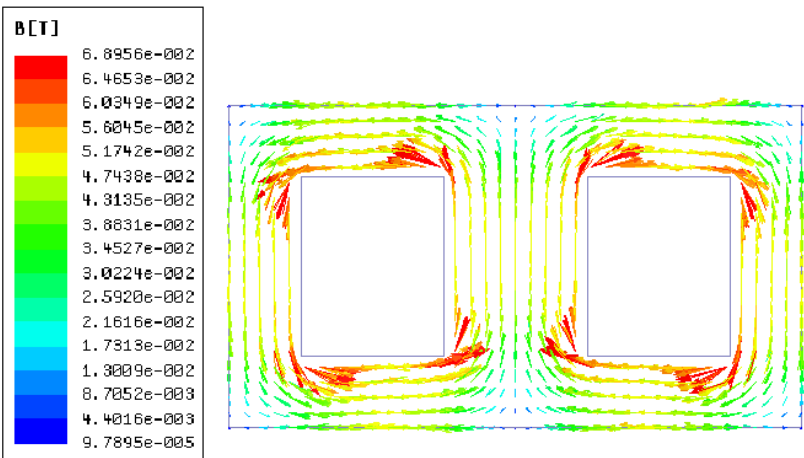

Fig. 11. Vector magnetic flux density in the core of the transformer.

It can be observed that current is more evenly distributed throughout the trail of copper with a consequent reduction of skin effect and improvement in efficiency.

In Fig. 11 you can view the distribution of vector magnetic flux density in the core of the transformer.

\section{CONCLUSIONS}

From the data obtained in simulation was possible to confirm that the transformer with PCB windings is an effective solution for applications where you want optimum performance at high frequencies and powers.

As previously mentioned, work is currently being developed and have not been made simulations taking into account the waveform of the inverter. The waveform is square, differently from discussed in this article.

Future studies can be made a more detailed study of the influence of skin effect and proximity effect in the calculation of transformers losses. 


\section{REFERENCES}

[1] G. Prieto, O. Prieto, C. Gay and I. T. Yamamoto, "Destruction of Residual Fumigant Using a Plasma Reactor", IEEE Transactions on Industry Applications, vol. 39, no. 1, pp. 72-78, january/february 2003.

[2] de Medeiros, Thiago Q., Alexandre M. F. Guimarães, Andrés O. Salazar and André L. Maitelli, "Automation system applied to a plasma inertization plant", Eletrônica de Potência - SOBRAEP, vol. 12, no. 1, pp. 19-25, march 2007.

[3] J. Li, Y.Shi, Z. Niu and D. Zhou "Modeling Simulation and Optimization Design of PCB Planar Transformer", in Proc. of ICEMS, vol. 3, pp.1736-1739, 2005.

[4] Dubut, J. P., Alexandre M. F. Guimarães, Marcelo Dantas Lopes, Pedro Ivo de A. do Nascimento, Andrés O. Salazar and André L. Maitelli "High Frequency Converter Based On Resonant Inverters For Exciting A $50 \mathrm{~kW}$ Inductive Coupled Plasma Torch", in Proc. of COBEP, pp. 71-76, 2005.

[5] C. Ebert, W. Carpes Jr and J. Fagundes, "Projeto de indutores e transformadores planares utilizados em fontes de alimentação chaveadas", in Proc. of Induscon, pp. 1-6, 2008. 